\title{
Analysis of Agricultural Eco-Efficiency and Influencing Factors in Henan Province
}

\author{
Bingjun Li, Wenyan Li*, Wenya Ma, Yifan Zhang \\ School of Information and Management Science, Henan Agricultural University, Zhengzhou, China \\ Email: zzlbjun@163.com, ^henau_wenyanli@163.com
}

How to cite this paper: Li, B. J., Li, W. Y., Ma, W. Y., \& Zhang, Y. F. (2022). Analysis of Agricultural Eco-Efficiency and Influencing Factors in Henan Province. Journal of Geoscience and Environment Protection, 10, 78-93.

https://doi.org/10.4236/gep.2022.101006

Received: November 28, 2021

Accepted: January 14, 2022

Published: January 17, 2022

Copyright $\odot 2022$ by author(s) and Scientific Research Publishing Inc. This work is licensed under the Creative Commons Attribution International License (CC BY 4.0).

http://creativecommons.org/licenses/by/4.0/

\begin{abstract}
In order to improve the agricultural eco-efficiency and promote the sustainable development of agriculture in Henan Province, China, based on the footprint theory, the super-efficiency SBM model is used to scientifically calculate and analyze the agricultural eco-efficiency in Henan Province. On this basis, the influencing factors of agricultural eco-efficiency in Henan Province are quantitatively analyzed by using the grey incidence analysis model. The results show that unilaterally considering one of grey water footprints and carbon footprints will overestimate or underestimate the agricultural eco-efficiency of Henan Province in different degrees in different time periods, and the agricultural eco-efficiency obtained by comprehensively considering grey water footprint and carbon footprint (GWCAEE) is more in line with the reality of agricultural development in Henan Province. In 2000-2004, GWCAEE in Henan Province was better. During 2005-2014, GWCAEE in Henan Province showed a fluctuating decline and continued to be in an inefficient state. From 2015 to 2019, GWCAEE of Henan Province gradually increased, and it became effective in 2019. In recent years, GWCAEE has developed well. Through the grey incidence analysis between 12 influencing factors including endogenous factors and exogenous factors and GWCAEE, it is found that the six leading factors of GWCAEE in Henan Province are agricultural structure, financial input for agriculture, number of agricultural employees, crop sown area, consumption of chemical pesticide, consumption of agricultural diesel oil. According to the above research conclusions, suggestions for improving agricultural eco-efficiency in Henan Province are put forward.
\end{abstract}

\section{Keywords}

Agricultural Eco-Efficiency, Grey Incidence Models, Grey Water Footprint, Carbon Footprint, Super-Efficiency SBM Model 


\section{Introduction}

In the past 40 years of reform and opening up, China's agricultural economy has developed rapidly, but at the same time, it has caused a series of environmental problems. At present, $17 \%$ of greenhouse gases and $50 \%$ of $\mathrm{CH}_{4}$ in China come from the agricultural sector, and agricultural carbon emissions have become the main source of carbon emissions in China (Hu et al., 2018). Non-point source pollution caused by overuse of chemical pesticides and fertilizers has become an important source of water pollution (Ding et al., 2021). The situation of agricultural ecological development is very severe. Water pollution and the increase of greenhouse gas emission caused by agricultural production have become two key environmental problems. Under this background, from the perspective of win-win economic and environmental benefits, it is of great significance to improve agricultural eco-efficiency (AEE) in order to solve the social contradiction between agricultural production and ecological environment protection and realize the sustainable development of agriculture.

Ecological efficiency (EE), also called environmental efficiency, was first proposed by Schaltergger \& Sturm in 1990 (Desimore \& Popoff, 1997), which means the ratio of increased value to increased environmental impact, and is an important indicator to measure sustainable development capability (Tian et al., 2014). Agricultural eco-efficiency is its expansion and extension in the field of agriculture (Wang \& Zhang, 2018). At present, scholars have not unified the definition of agricultural eco-efficiency, but its connotation is to minimize the input of agricultural resources and environmental pollution on the premise of ensuring the development of agricultural economy, and advocate a development model of ecological agriculture with the concept of "high efficiency, saving resources and reducing pollution" (Cao \& Zeng, 2019). At present, there are researches on agricultural eco-efficiency at home and abroad, mainly focusing on ecological efficiency evaluation (Wang \& Zhang, 2016; Khan \& Ullah 2020; Expósito \& Velasco 2020), influencing factor analysis (Han, 2013; Tian \& Wang, 2016; Liu \& Song 2019), environmental regulation (Li et al., 2011; Chen et al., 2017) and emission reduction potential (Li et al., 2017; Zhu et al., 2018).

In the existing research, when scholars use the unexpected output SBM (Slack-Based Measure ) model to evaluate agricultural eco-efficiency, there are great differences in the choice of unexpected output indicators. Among them, in the research of taking agricultural non-point source pollution as the unexpected output index, Pan and Ying (2013) measured the agricultural eco-efficiency in China from 1998 to 2009, and found that although the agricultural eco-efficiency in China showed an upward trend, the overall level was low, and the main reasons for the efficiency loss were excessive consumption of resources and excessive discharge of pollutants. $\mathrm{Li}$ (2014) calculated the agricultural eco-efficiency in China from 1978 to 2008, and thought that the agricultural eco-efficiency increased obviously during the transition period, so we should look for a breakthrough in the agricultural eco-efficiency revolution from the perspective of in- 
stitutional innovation. Taking the water pollution as the unexpected output, Wang and Lin (2021) made an empirical analysis on the spatial evolution characteristics and driving factors of China's agricultural eco-efficiency from 1990 to 2016, and found that China's agricultural eco-efficiency obviously decreased and there were obvious regional characteristics. Fu et al. (2021) calculated the agricultural environmental efficiency of Dongting Lake, the main grain producing area, and found that the agricultural environmental efficiency was relatively low under the constraint of water pollution from 1994 to 2014, and the overall growth trend was fluctuating, and the gray water footprint had high emission reduction potential. In the research of taking agricultural carbon emissions as the unexpected output, Liu et al. (2014) measured the agricultural eco-efficiency in China from 2000 to 2010, and found that the agricultural eco-efficiency has been greatly improved, while there are regional differences. Wang et al. (2020) calculated the carbon footprint of corn production by considering the carbon footprint model of straw burning in open air, and made an empirical study on the environmental efficiency of corn production in Heilongjiang Province from 2004 to 2017. It was found that the environmental efficiency of corn production after considering straw burning in open air decreased obviously, showing different characteristics in different time periods, but the overall trend was fluctuating and declining. Tian et al., (2014) calculated the agricultural eco-efficiency in China from 2002 to 2012, and found that the agricultural eco-efficiency in the eastern region was generally higher, and the potential for carbon emission reduction in the central region was stronger. Zhang et al. (2021) calculated the agricultural eco-efficiency of Shandong Province from 2000 to 2017 with agricultural carbon emissions and agricultural non-point source pollution as the unexpected output indicators, and found that the efficiency of Shandong Province was higher overall, but the regional differences were obvious.

On the whole, the existing research results are different because of the different index system and different emphasis. Some scholars have combined agricultural non-point source pollution with agricultural carbon emissions, and considered the pollution degree caused by agricultural production relatively comprehensively. However, there are relatively few studies on agricultural eco-efficiency from the perspective of water-carbon at present. In view of the current research situation of agricultural eco-efficiency, this paper will take narrow agriculture (planting industry) in Henan Province as the research object, from the angle of water environment and climate of agricultural production, and take the combination of grey water footprint and carbon footprint as the undesired output of agricultural production, and comprehensively investigate the ecological environment efficiency of agricultural production based on the influence of agricultural production activities on water environment and climate warming. Then, look for the exogenous factors that affect the agricultural eco-efficiency of Henan Province. Grey incidence models are used to explore the influence degree of each influencing factor on agricultural eco-efficiency. 
The rest of this paper is organized as follows: the research methods and data sources are introduced in Section 2. The agricultural eco-efficiency of Henan Province is systematically evaluated in Section 3. Grey incidence analysis of agricultural eco-efficiency and influencing factors in Henan Province is carried out in Section 4. And section 5 makes conclusions to the paper.

\section{Research Methods and Data}

\subsection{Grey Water Footprint and Carbon Footprint Measurement Method}

\subsubsection{Calculation Method of Grey Water Footprint}

Footprint research is one of the hot spots in the field of ecological economics and sustainable development (Fang, 2015). Footprint indicators provide a new idea and way to evaluate the resource consumption and waste discharge of agricultural production. According to the Water Footprint Evaluation Manual published by the International Water Footprint Network, the grey water footprint (GWF) is defined as the volume of fresh water needed to absorb and assimilate a certain pollutant load based on the natural background concentration and existing water quality standards (Hoekstra et al., 2011). The footprint of agricultural grey water mainly refers to the chemical fertilizer and pesticides applied in the process of crop growth, and other elements such as nitrogen, phosphorus and potassium enter the water through runoff process, causing water pollution (Gai et al., 2010).

Nitrogen fertilizer and phosphate fertilizer are mainly used in planting activities in Henan Province, so nitrogen fertilizer and phosphate fertilizer are selected as water pollutants in this paper. The agricultural grey water footprint of Henan Province is the larger of grey water footprint of nitrogen fertilizer and grey water footprint of phosphate fertilizer. The calculation process mainly refers to the Water Footprint Evaluation Manual, and the specific calculation formula is as follows:

$$
\begin{aligned}
& G W F_{\text {pla }}=\max \left(G W F_{(N)}, G W F_{(P)}\right) \\
& G W F_{(i)}=\frac{L_{(i)}}{C_{\text {max }}-C_{\text {nat }}}=\frac{\alpha_{(i)} \times A p p l_{(i)}}{C_{\text {max }}-C_{\text {nat }}}
\end{aligned}
$$

In the above formulas, $G W F_{p l a}$ is the footprint of agricultural grey water, $G W F_{(N)}$ is the footprint of nitrogen fertilizer grey water, and $G W F_{(P)}$ is the footprint of phosphate fertilizer grey water. $L_{(i)}$ refers to the discharge load of the $i$ pollutant $(\mathrm{kg}), A_{(p p l}$ refers to the mass of the $i$ chemical applied $(\mathrm{kg})$, $\alpha_{(i)}$ refers to the leaching rate of pollutants, $C_{\max }$ refers to the highest concentration of pollutants $(\mathrm{mg} / \mathrm{L})$ under the environmental standard of water quality, and $C_{\text {nat }}$ refers to the initial concentration of the receiving water body $(\mathrm{mg} / \mathrm{L}),(i=N / P)$. In the calculation of grey water footprint, the discharge standard of various pollutants adopts the Class III water standard specified in the Environmental Quality Standard for Surface Water (GB3838-2002) (State 
Environmental Protection Administration and General Administration of Quality Supervision, Inspection and Quarantine, 2002). The maximum discharge standard mass concentrations of nitrogen and phosphorus pollutants are $1 \mathrm{mg} / \mathrm{L}$ and $0.05 \mathrm{mg} / \mathrm{L}$ respectively, and the natural background mass concentration value is $0 \mathrm{mg} / \mathrm{L}$. The loss rates of nitrogen fertilizer and phosphorus fertilizer are respectively $86.7 \%$ and $36 \%$ (Tong, 2019).

\subsubsection{Carbon Footprint Measurement Method}

Carbon Footprint (CF) refers to the direct and indirect greenhouse gas emissions produced by a product or a service in the whole life cycle (or geographical scope) (Liu et al., 2013), which is an index to measure the carbon emission level and can indicate the carbon emissions of different functional units. The calculation of carbon footprint plays an important role in evaluating the emission reduction potential of agricultural production and creating a low-carbon production model.

According to the methods of IPCC (2007) sythesis report (IPCC, 2007) and the existing literature (Li \& Zhang, 2012; Tian et al., 2015), the agricultural carbon emissions mainly come from six aspects namely, chemical fertilizer, pesticide, plastic film for agriculture, diesel oil, ploughing and agricultural irrigation, which will produce carbon emissions during the use of them. The calculation formula of agricultural carbon emissions is as follows:

$$
E=\sum E_{i}=\sum T_{i} \cdot \delta_{i}
$$

In the above formula, $E$ is the total amount of agricultural carbon emissions, $E_{i}$ is the carbon emissions of various agricultural carbon sources, $T_{i}$ is the consumption of agricultural energy, and $i$ is the carbon emission coefficient of various agricultural carbon sources (Table 1). $i$ respectively represent chemical fertilizer, chemical pesticide, plastic film for agriculture, diesel oil, ploughing and agricultural irrigation.

Table 1. Sources, coefficients and reference sources of agricultural carbon emissions.

\begin{tabular}{ccl}
\hline $\begin{array}{c}\text { Carbon emission } \\
\text { source }\end{array}$ & $\begin{array}{c}\text { Carbon emission } \\
\text { coefficient }\end{array}$ & \multicolumn{1}{c}{ Reference source } \\
\hline Chemical fertilizer & $0.8956 \mathrm{~kg} / \mathrm{kg}$ & $\begin{array}{l}\text { West and Marland, (2002), Oak Ridge } \\
\text { National Laboratory }\end{array}$ \\
Chemical pesticide & $4.9341 \mathrm{~kg} / \mathrm{kg}$ & $\begin{array}{l}\text { Oak Ridge National Laboratory (Zhi \& Gao, } \\
\text { 2009) }\end{array}$ \\
$\begin{array}{c}\text { Plastic film for } \\
\text { agriculture }\end{array}$ & $5.18 \mathrm{~kg} / \mathrm{kg}$ & $\begin{array}{l}\text { Nanjing agricultural university institute of } \\
\text { agricultural resources and ecology }\end{array}$ \\
Diesel oil & $0.5927 \mathrm{~kg} / \mathrm{kg}$ & $\begin{array}{l}\text { Intergovernmental Panel on Climate and } \\
\text { Climate (IPCC, 2007) }\end{array}$ \\
Ploughing & $312.6 \mathrm{~kg} / \mathrm{km}^{2}$ & $\begin{array}{l}\text { College of Biology and Technology, China } \\
\text { Agricultural University (Wu et al., 2007) }\end{array}$ \\
Agricultural irrigation & $266.48 \mathrm{~kg} / \mathrm{hm}^{2}$ & \begin{tabular}{l} 
West and Marland, (2002) \\
\hline
\end{tabular} \\
\hline
\end{tabular}




\subsection{Super-Efficiency SBM Model Based on Unexpected Output}

SBM (Slack-Based Measure) model based on unexpected output was first proposed by Tone in 2001 (Tone, 2001). SBM model adds slack variables to the objective function, which solves the slack problem of input and output in efficiency evaluation when there is unexpected output. However, for DMUs with efficiency of 1, SBM model is difficult to further distinguish the differences between effective DMUs. On the basis of SBM model, Tone (2002) further defined that the super-efficiency SBM model could further compare and distinguish the efficient DMU at the front. Assuming that there are $n$ DMUs in the super-efficiency SBM model of undesired output, each DMU has $m$ inputs, outputs and undesired outputs, the super-efficient SBM-undesirable model is expressed as follows (Tone, 2002).

$$
\begin{gathered}
\min \rho=\frac{1+\frac{1}{m} \sum_{i=1}^{m} \frac{s_{i}^{-}}{x_{i k}}}{1-\frac{1}{q_{1}+q_{2}}\left(\sum_{i=1}^{m} \frac{s_{r}^{+}}{y_{r k}}+\sum_{i=1}^{m} \frac{s_{i}^{b-}}{b_{t k}}\right)} \\
\text { s.t. }\left\{\begin{array}{l}
\sum_{j=1, j \neq k}^{n} x_{j} \lambda_{j}-s_{i}^{-} \leq x_{i k} \\
\sum_{j=1, j \neq k}^{n} y_{j} \lambda_{j}-s_{i}^{+} \geq y_{r k} \\
i=1,2, \cdots, m, \quad r=1,2, \cdots, q_{1}, \quad t=1,2, \cdots, q_{2}, j=1,2, \cdots, n(j \neq k) \\
1-\frac{1}{q_{1}+q_{2}}\left(\sum_{r=1}^{b-} \frac{s_{r}}{y_{r k}}+\sum_{t=1}^{q_{2}} \frac{s_{t}^{b-}}{b_{t k}}\right)>0 \\
\lambda_{j}, s_{i}^{-}, s_{r}^{+}, s_{t}^{b-} \geq 0
\end{array}\right.
\end{gathered}
$$

In the above formula, $\rho$ is the ecological efficiency value, $j$ is each DMU, and $\lambda_{j}$ is the weight vector. $s_{i}^{-}, s_{r}^{+}$and $s_{t}^{b-}$ respectively represent the slack variables of input, expected output and unexpected output, $x_{j}, y_{j}$ and $b_{j}$ are the input, expected output and unexpected output variables of the $j$-th DMU, and $x_{i k}, y_{i k}$ and $b_{i k}$ respectively represent the input, expected output and unexpected output variables of the evaluation $D M U_{k}, \rho \geq 1$ means that the DMU is completely effective, otherwise, it indicates that there is efficiency loss, and it is necessary to adjust the input and output.

According to the existing research (Hou \& Yao, 2018; Wang \& Zhang, 2018), combined with the specific situation of agricultural production in Henan Province, the input of land, manpower, machinery, pesticides, fertilizers and other resources is taken as the input index, the gross value of agriculture, forestry, animal husbandry and fishery is taken as the expected output index, and the unexpected output index selects the agricultural grey water footprint and carbon footprint. The evaluation index system of agricultural eco-efficiency in Henan Province is shown in Table 2. 
Table 2. Evaluation index system of agricultural eco-efficiency in Henan Province.

\begin{tabular}{|c|c|c|c|}
\hline Indicators & Variable & Variable declaration & Remarks \\
\hline \multirow{7}{*}{ Input index } & Land input & Planting area of crops $\left(10^{3} \mathrm{ha}\right)$ & Reflect the actual cultivated area \\
\hline & Labor input & Number of agricultural employees ( $10^{4}$ persons) & Situation of agricultural human resources \\
\hline & Mechanical input & Total power of agricultural machinery $\left(10^{4} \mathrm{kw}\right)$ & Investment of agricultural machinery \\
\hline & Fertilizer input & Consumption of chemical fertilizer $\left(10^{4} \mathrm{t}\right)$ & $\begin{array}{l}\text { Important pollutants in water environment } \\
\text { and sources of carbon emissions }\end{array}$ \\
\hline & Pesticide input & Consumption of chemical Pesticide $\left(10^{4} \mathrm{t}\right)$ & $\begin{array}{l}\text { Important pollutants in water environment } \\
\text { and sources of carbon emissions }\end{array}$ \\
\hline & Mulch film input & Plastic film use for agriculture $\left(10^{4} \mathrm{t}\right)$ & Important sources of carbon emissions \\
\hline & Diesel oil input & Diesel oil use for agricultural $\left(10^{4} \mathrm{t}\right)$ & Important sources of carbon emissions \\
\hline \multirow{3}{*}{$\begin{array}{l}\text { Output } \\
\text { indicators }\end{array}$} & Expected output & $\begin{array}{l}\text { Gross value of agriculture, forestry, animal } \\
\text { husbandry and fishery ( } 100 \text { million yuan) }\end{array}$ & Agricultural economic level \\
\hline & \multirow{2}{*}{ Unexpected output } & Grey water footprint $\left(10^{10} \mathrm{~m}^{3}\right)$ & Agricultural water pollution \\
\hline & & Carbon footprint $\left(10^{4} \mathrm{t}\right)$ & Carbon emissions \\
\hline
\end{tabular}

\subsection{Grey Incidence Model}

Grey system theory is a systematic analysis method, first proposed by Professor Deng Julong, which can solve the problem of poor information and uncertainty. The basic idea of grey incidence analysis method is to judge whether there is a close relationship between different sequences according to the geometric similarity between the system behavior sequence and the system factor sequences. The more similar the geometric features of curve, the greater the correlation between the system behavior sequence and the factor sequence, and the greater the influence of the system behavior sequence by the system factor sequence, so the system factor is the main influencing factor, otherwise it is the secondary influencing factor (Liu et al., 2018).

In this paper, GWCAEE is set as the system behavior characteristic sequence $X_{0}=\left\{x_{0}(1), x_{0}(2), \cdots, x_{0}(n)\right\}$, and each influencing factor is set as the system factor sequence, which is denoted as, $i=1,2, \cdots, m$, where $n$ is the length of time series $X_{i}=\left\{x_{i}(1), x_{i}(2), \cdots, x_{i}(n)\right\}$ and $n=20$. The specific steps are as follows:

1) The original behavior feature sequence and system factor sequences are as follows:

$$
X_{i}=\left\{x_{i}(1), x_{i}(2), \cdots, x_{i}(n)\right\}, \quad i=0,1,2, \cdots, m
$$

2) Let the initial image of each sequence:

$$
X_{i}^{\prime}=\frac{X_{i}}{x_{i}(1)}=\left(x_{i}^{\prime}(1), x_{i}^{\prime}(2), \cdots, x_{i}^{\prime}(n)\right), \quad i=0,1,2, \cdots, m
$$

3) Finding out the absolute value sequence of the difference value between the components corresponding to the initial image of $X_{0}$ and $X_{i}$, and write: 


$$
\Delta_{i}(k)=\left|x_{0}^{\prime}(k)-x_{i}^{\prime}(k)\right|, \quad \Delta_{i}=\left(\Delta_{i}(1), \Delta_{i}(2), \cdots, \Delta_{i}(n)\right), \quad i=0,1,2, \cdots, m
$$

4) Calculate the maximum and minimum value of $\Delta_{i}(k)=\left|x_{0}^{\prime}(k)-x_{i}^{\prime}(k)\right|$, $k=1,2, \cdots, m$. Let

$$
M=\max _{i} \max _{k} \Delta_{i}(k), \quad m=\min _{i} \min _{k} \Delta_{i}(k)
$$

5) Calculate the correlation coefficients:

$$
\gamma_{0 i}=\frac{m+\xi M}{\Delta_{i}(k)+\xi M}, \quad \xi \in(0,1), \quad k=1,2, \cdots, n, \quad i=0,1,2, \cdots, m
$$

6) Calculate the average value of correlation coefficients, which is the required degree of grey incidence:

$$
\gamma_{0 i}=\frac{1}{n} \sum_{k=1}^{n} \gamma_{0 i}(k), \quad i=0,1,2, \cdots, m
$$

\subsection{Data Source}

The basic data needed to calculate the grey water footprint, carbon footprint, and calculate the agricultural eco-efficiency by super-effiency SBM model come from Henan Statistical Yearbook and Qianzhan Network Database.

\section{Calculation of Agricultural Eco-Efficiency in Henan Province Based on Super-Efficiency SBM Model}

The agricultural eco-efficiency of Henan Province with grey water footprint and as carbon footprint undesired output (GWAEE), with carbon footprint as undesired output (CAEE) and with grey water footprint and carbon footprint as undesired output (GWCAEE) are respectively calculated by super-efficiency SBM model. The calculation results are shown in Table 3.

Vertically, there are obvious differences between agricultural eco-efficiency based on different perspectives, and the differences among them are different in

Table 3. Agricultural eco-efficiency of Henan Province from 2000 to 2019 in different footprint perspectives.

\begin{tabular}{cccccccc}
\hline Year & GWCAEE & GWAEE & CAEE & Year & GWCAEE & GWAEE & CAEE \\
\hline 2000 & 1.0000 & 1.0000 & 1.0000 & 2010 & 0.7810 & 0.7441 & 0.7964 \\
2001 & 1.0000 & 1.0000 & 1.0000 & 2011 & 0.7783 & 0.7469 & 0.8035 \\
2002 & 0.8858 & 0.8521 & 0.8732 & 2012 & 0.7820 & 0.7590 & 0.8159 \\
2003 & 1.0000 & 1.0000 & 1.0000 & 2013 & 0.7768 & 0.7435 & 0.8088 \\
2004 & 1.0000 & 1.0000 & 1.0000 & 2014 & 0.7766 & 0.7421 & 0.8079 \\
2005 & 0.9168 & 0.8923 & 0.9146 & 2015 & 0.7797 & 0.7500 & 0.8073 \\
2006 & 0.7946 & 0.7347 & 0.7750 & 2016 & 0.8162 & 0.8077 & 0.8486 \\
2007 & 0.7843 & 0.7214 & 0.7627 & 2017 & 0.8530 & 0.8411 & 0.8784 \\
2008 & 0.8047 & 0.7554 & 0.8014 & 2018 & 0.9156 & 0.9071 & 0.9186 \\
2009 & 0.7757 & 0.7334 & 0.7802 & 2019 & 1.0543 & 1.0837 & 1.0702 \\
\hline
\end{tabular}


different time periods. Except for the four years of 2000, 2001, 2003 and 2004, GWCAEE, GWAAEE and CAEE are all equal to 1.000, but in other years, they are different. During 2000-2019, GWAEE was less than GWCAEE, but it was greater than GWCAEE in 2019. In 2000-2009, CAEE was always less than GWCAEE, but in 2010-2019, CAEE was always greater than GWCAEE. However, in the process of agricultural production, the impacts on the environment are various, and the unexpected outputs are various. So the difference between them shows that if only a single footprint index is considered, the agricultural eco-efficiency will be underestimated or overestimated in different time periods, which will lead to the unscientific and inaccurate agricultural eco-efficiency.

Horizontally, the trends of GWCAEE, GWAEE and CAEE in Henan Province in Figure 1 are basically the same. On the whole, the GWCAEE in Henan Province is generally low, except in the five years of 2000, 2001, 2003, 2004 and 2019, the GWCAEE in Henan Province is effective, and in the other 15 years, the agricultural input, output and environmental protection in Henan Province are in a non-dynamic equilibrium state. By stages, from 2000 to 2004, the agricultural eco-efficiency of Henan Province was good, but in 2002, due to the impact of SARS, the agricultural economy of Henan Province suffered a severe setback, and the agricultural eco-efficiency could not be effective. During 2005-2014, the agricultural eco-efficiency of Henan Province showed a fluctuating decline and remained in an inefficient state. The reason is that with the rapid development of economy and society, the opportunity cost of farmers' farming is rising, so farmers will inevitably choose to work in cities from a "rational" point of view, and the young and middle-aged rural labor force is constantly shifting, which leads to the continuous decline of crop planting area and the serious phenomenon of farmland abandonment and idleness. In addition, during the research period, agricultural production mostly relied on the extensive production mode of high input, high consumption, high pollution and low output, and at the expense of

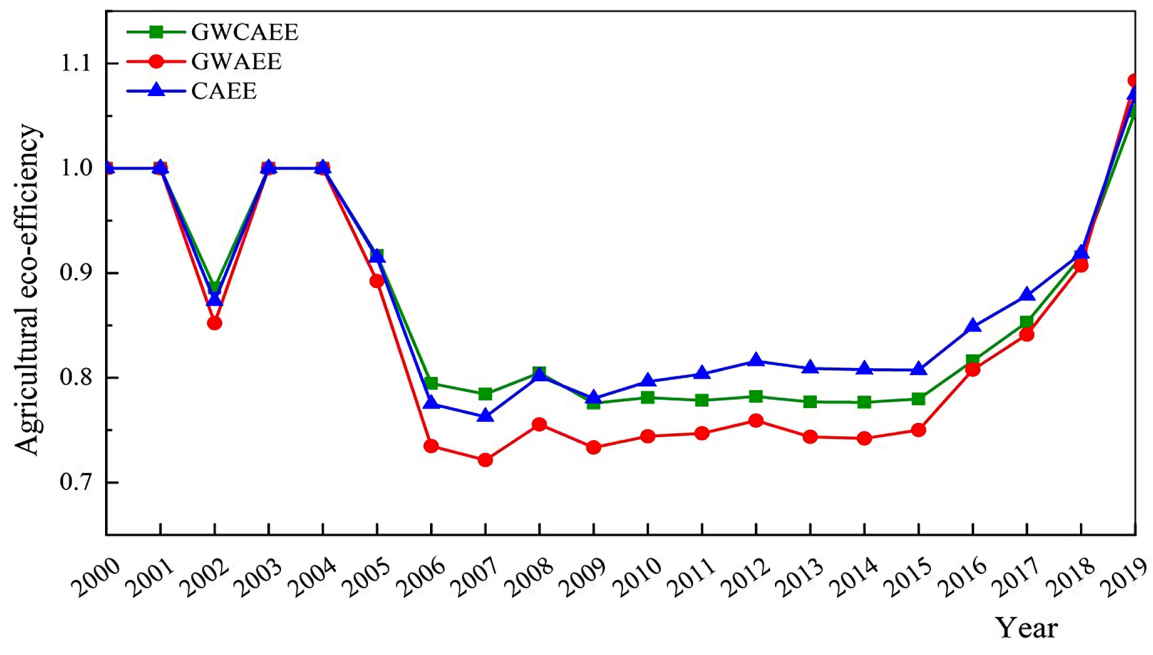

Figure 1. Agricultural eco-efficiency of Henan Province from 2000 to 2019 in different footprint perspectives. 
resources and environment in exchange for agricultural economic growth, making agriculture. From 2015 to 2019, the agricultural eco-efficiency of Henan Province gradually increased, and it was effective in 2019. With the intensification of agricultural non-point source pollution, the Ministry of Agriculture and Rural Affairs launched a tough battle to control agricultural non-point source pollution in 2015, and put forward the target task of "one control, two reductions and three basics" to achieve total agricultural water control, reduction of fertilizer and pesticide usage and basic resource utilization of livestock manure, straw and plastic film by 2020. During this period, various agricultural non-point source pollution control work in Henan Province achieved positive results, and in 2019, agricultural input, output and environmental protection reached a dynamic balance.

\section{Grey Incidence Analysis of GWCAEE and Influencing Factors}

In the process of agricultural production, endogenous factors such as the sown area of crops, the application amount of pesticides and chemical fertilizers directly determine the agricultural output value and ecological efficiency. Similarly, external social factors such as the degree of economic development and financial input will indirectly affect agricultural production and ecological efficiency. The specific exogenous factors are explained as follows:

\subsection{Selection of Endogenous Influencing Factors}

Take the input indicators in the evaluation system of agricultural eco-efficiency in Table 2 as endogenous factors. TPAM represents total power of agricultural machinery. CSA represents crop sown area. CCP is the consumption of chemical pesticide. CCF represents the consumption of chemical fertilizer. CADO is consumption of agricultural diesel oil. CAPF represents the consumption of agricultural plastic film.

\subsection{Selection of Exogenous Influencing Factors}

Agricultural structure (AAS): every region is constantly optimizing the agricultural industrial structure according to the changes of policies and overall planning, thus affecting the agricultural eco-efficiency. Therefore, the ratio of output value of planting industry to output value of agriculture, forestry, animal husbandry and fishery is selected as the data of agricultural structure.

Agricultural technological progress (ATP): Agricultural technological innovation can improve agricultural workers' technical literacy, crops, soil and agricultural materials and other technical indicators, making agricultural production more efficient and consuming less materials. The ratio of research and development (R \& D) expenditure to GDP of Henan is adopted as technological progress.

Urbanization rate (UR): At present, Henan is in an accelerated period of urbanization. The continuous improvement of urbanization will have an impact 
on agricultural land area, planting area and labor mobility direction. At the same time, with the improvement of urbanization rate, it will also have a positive impact on farmers' awareness of green production and scientific application of chemical fertilizers and pesticides.

Financial input for agriculture (FIA): To a certain extent, financial input will affect farmers' enthusiasm for agricultural production activities, the perfection of agricultural infrastructure and the process of agricultural modernization. Because there is no special financial input data, the financial support for agriculture is used instead, and the financial support for agriculture, forestry and water affairs expenditure accounts for the proportion of local financial expenditure.

Industrialization level (IL): On the one hand, industrialization has laid the foundation for upgrading modern agriculture. On the other hand, industrialization will occupy cultivated land, at the same time, it will promote the transfer of agricultural labor force, change the industrial structure, and have a certain impact on agricultural production. The industrialization level is expressed by the proportion of industrial added value to GDP of Henan.

\subsection{Results and Analysis Base on Grey Incidence Models}

Taking GWCAEE in Henan Province from 2000 to 2019 as the behavioral sequence and the influencing factors from 2000 to 2019 as the factor sequences, degree of grey incidence between GWCAEE and different influencing factors are calculated by the grey incidence model, and the results of grey incidence between GWCAEE in Henan Province and 12 influencing factors under the indicators of endogenous factors and exogenous factors are obtained, as shown in Table 4.

Table 4. Degree of grey incidence between GWCAEE and influencing factors.

\begin{tabular}{ccc}
\hline Primary factor & Secondary factor & Degree of grey incidence \\
\hline & TPAM & $0.8520(10)$ \\
CSA & $0.9490(3)$ \\
Endogenous factors & CCP & $0.9223(4)$ \\
& CCF & $0.8789(8)$ \\
& CADO & $0.9128(5)$ \\
CAPF & $0.8753(9)$ \\
\hline \multirow{3}{*}{ Exogenous factors } & NAE & $0.9708(2)$ \\
& AS & $0.9727(1)$ \\
& ATP & $0.8295(12)$ \\
FIA & $0.9098(6)$ \\
& IL & $0.8934(7)$ \\
UR & $0.8440(11)$ \\
\hline
\end{tabular}

Note: the values in brackets are the ranking of the degree of grey incidence models in $\mathrm{Ta}$ ble 4 . 
It can be seen from Table 4 that the results of grey incidence models between GWCAEE and various influencing factors. The rank of the degree of grey incidence between influencing factors and GWCAEE is as follows: agricultural structure $>$ number of agricultural employees $>$ crop sown area $>$ consumption of chemical pesticide $>$ consumption of agricultural diesel oil $>$ financial input for agriculture $>$ industrialization level $>$ consumption of chemical fertilizer $>$ consumption of agricultural plastic film $>$ total power of agricultural machinery $>$ urbanization rate $>$ agricultural technological progress.

In this paper, the influencing factors of endogenous factors and exogenous factors whose degree of grey incidence with GWCAEE is over 0.9000 are selected as the leading factors of GWCAEE in Henan province. According to the results of degree of grey incidence, endogenous factors include four dominant factors, namely number of agricultural employees, crop sown area, consumption of chemical pesticide, consumption of agricultural diesel oil.

With the development of economy, young rural laborers go out to work or engage in other jobs. Old and weak laborers who stay in rural areas will replace the loss of young and strong laborers by using a large number of chemical elements such as pesticides and fertilizers, thus increasing agricultural output and gaining more agricultural income. This aggravates non-point source pollution and agricultural carbon emissions, and has obvious influence on agricultural ecological benefits. Crop sown area not only determines the grain output, but also affects the agricultural eco-efficiency. On the one hand, land ploughing in agricultural production will also cause carbon emissions; on the other hand, the larger the planting area, the more inputs of chemical fertilizers, pesticides, agricultural films and other materials needed for agricultural production will also increase the environmental burden, which will have a greater impact on agricultural ecological benefits. Chemical fertilizer is the main source of agricultural carbon footprint, and the carbon emissions from chemical fertilizer account for $60 \%$ of the total agricultural carbon emissions. Meanwhile, the grey water footprint in Henan Province mainly comes from the loss during the use of chemical fertilizer, so the double impact of chemical fertilizer on ecological environment leads to the long-term ineffectiveness of GWCAEE in Henan Province. The consumption of diesel oil can reflect the degree of agricultural mechanization. The improvement of mechanization degree can improve labor productivity and save labor cost, but the large-scale utilization of petrochemical resources will bring serious pollution to the soil and atmosphere, thus profoundly affecting the agricultural eco-efficiency.

The exogenous factors include two dominant factors, namely agricultural structure and financial input for agriculture, but the agricultural structure has the most significant effect on GWCAEE, with the degree of grey incidence of 0.9727, ranking first. This shows that agricultural structure is the key to influence GWCAEE in Henan Province.

The structure of agriculture not only reflects the scale of planting, but also re- 
flects the economic development level of planting to a great extent. Economic benefit is the core purpose of agricultural production, and all agricultural production activities are carried out for this purpose. A developed agricultural economy can promote the progress of agricultural technology, promote the upgrading of mechanical power, improve the utilization efficiency of energy and machinery, renew and reduce the input of agricultural materials, and achieve the purpose of reducing pollution. Therefore, rationally adjusting the agricultural structure is the fundamental driving force to improve the efficiency of ecological agriculture. Financial support for agriculture also has a great influence on agricultural eco-efficiency. To a certain extent, the support of government funds will affect the enthusiasm of farmers in agricultural production activities, the improvement of agricultural infrastructure and the process of agricultural modernization.

\section{Conclusion and Suggestions}

After studying the agricultural eco-efficiency of Henan Province from 2000 to 2019 , the following conclusions were found: unilaterally considering one of grey water footprints and carbon footprints (GWAEE or CAEE) will overestimate or underestimate the agricultural eco-efficiency of Henan Province in different time periods, and the ecological efficiency obtained by comprehensively considering grey water footprint and carbon footprint (GWCAEE) is more in line with the reality of agricultural development in Henan Province. On the whole, during the research period, GWCAEE in Henan Province was not ideal, and in most years, it was in an inefficient state. From 2000 to 2004, the agricultural eco-efficiency of Henan Province was good. From 2005 to 2014, the agricultural eco-efficiency of Henan Province showed a fluctuating downward trend and was in a state of low efficiency. From 2015 to 2019, the agricultural eco-efficiency of Henan Province gradually improved, and it was effective in 2019. Through the grey incidence analysis of 12 influencing factors under endogenous and exogenous indicators, it is found that the six leading factors of GWCAEE in Henan Province are agricultural structure, number of agricultural employees, crop sown area, consumption of chemical pesticide, consumption of agricultural diesel oil, financial input for agriculture. According to the above research conclusions, the countermeasures to improve the agricultural ecological efficiency in Henan Province were put forward.

1) Adjust the agricultural structure rationally. According to the analysis results of this paper, the agricultural structure has a great influence on the agricultural ecological efficiency. The government should make scientific and reasonable agricultural production plans, abandon the simple pursuit of economic benefits, and pursue the coordinated development of economy and ecology as the ultimate goal, and take the road of sustainable agricultural development.

2) Farmers' awareness of environmental protection should be strengthened and the agricultural ecological environment should be gradually improved. Far- 
mers are the main body of agricultural production activities, it is necessary for farmers, especially older farmers, to receive multi-level and multi-form science and technology education, cultivate farmers' awareness of ecological environment protection and improve the technical level of using chemical fertilizers, pesticides and plastic films in agriculture, so as to reverse the disadvantage of low utilization rate of agricultural resources such as chemical fertilizers and pesticides in China.

3) Agricultural resources should be used reasonably, and environmental protection supervision should be strengthened. Not only the use of agricultural chemical materials and mechanical power should be reasonably controlled, but also the investment in the treatment of agricultural pollutants and the comprehensive treatment of rural ecological environment should be increased. At the same time, environmental safety supervision and management of pesticide and fertilizer use should be strengthened. Penalties for environmental violations should be increased, and the problems of "low illegal cost and high law-abiding cost" in the punishment of environmental violations need to be solved.

\section{Supported}

This work was supported by the Soft-Science Foundation of Henan Provincial Research Key Project (202400410051).

\section{Conflicts of Interest}

The authors declare no conflicts of interest regarding the publication of this paper.

\section{References}

Cao, J. W., \& Zeng, K. (2019). Study on Agricultural Eco-Efficiency and Its Influencing Factors in the Yangtze River Economic Belt from the Perspective of Low Carbon. Ecological Economy, 35, 115-119+127.

Chen, H., Guang, B., \& Sun, W. J. (2017). Research on Agricultural Production Efficiency under Different Environmental Regulations in Major Grain Producing Areas in China. Commercial Research, No. 3, 167-174.

Desimore, L. D., \& Popoff, F. (1997). World Business Council for Sustainable Development (WBCSD). Eco-Efficiency: The Business Link to Sustainable Development. WITP Press.

Ding, X., Cai, Z., \& Fu, Z. (2021). Does the New-Type Urbanization Construction Improve the Efficiency of Agricultural Green Water Utilization in the Yangtze River Economic Belt? Environmental Science and Pollution Research, 28, 64103-64112. https://doi.org/10.1007/s11356-021-14280-Z

Expósito, A., \& Velasco, F. (2020). Exploring Environmental Efficiency of the European Agricultural Sector in the Use of Mineral Fertilizers. Journal of Cleaner Production, 353, Article ID: 119971. https://doi.org/10.1016/j.jclepro.2020.119971

Fang, K. (2015). Footprint Family: Concept, Classification, Theoretical Framework and Integrated Pattern. Acta Ecologica Sinica, 35, 1647-1659.

https://doi.org/10.5846/stxb201305211128 
Fu, Y. H., Liu, T., Liu, J. Q., Hu, H., \& Wei, F. Q. (2021). Measurement and Evaluation of Agricultural Environmental Efficiency and Environmental Sustainability for Water in the Major Grain-Producing Area Based on Grey Water Footprint. Chinese Journal of Agricultural Resources and Regional Planning, 42, 77-87.

Gai, L. Q., Xie, G. D., Li, S. M., Zhang, C. X., \& Chen, L. (2010). A Study on Production Water Footprint of Winter-Wheat and Maize in the North China Plain. Resources Science, 32, 2066-2071.

Han, H. B. (2013). Agricultural Environmental Technical Efficiency and Its Determinants across Provinces in China. Research on Economics and Management, No. 9, 61-68.

Hoekstra, A. Y., Chapagain, A. K., Aldaya, M. M., \& Mekonnen, M. M. (2011). The Water Footprint Assessment Manual. Earthscan.

Hou, M. Y., \& Yao, S. B. (2018). Spatial-Temporal Evolution and Trend Prediction of Agricultural Eco-Efficiency in China from 1978 to 2016. Acta Geographica Sinica, 73, 2168-2183.

Hu, C., Wei, Y. Y., \& Hu, W. (2018). Research on the Relationship Agricultural Policy, Technological Innovation and Agricultural Carbon Emissions. Issues in Agricultural Economy, No. 9, 66-75.

IPCC (2007). Climate Change: 2007 Sythesis Report. IPCC Press.

Khan, D., \& Ullah, A. (2020). Comparative Analysis of the Technical and Environmental Efficiency of the Agricultural Sector: The Case of Southeast Asia Countries. Custos E Agronegocio on Line, 16, 2-28.

Li, B., \& Zhang, J. B. (2012). Decoupling of China's Agriculture Carbon Emissions and Economic Development Based on the Input Perspective. Economic Survey, No. 4, 27-31.

Li, G. C. (2014). The Green Productivity Revolution of Agriculture in China from 1978 to 2008. China Economic Quarterly, 13, 537-558.

Li, G. C., Fan, L. X., \& Min, R. (2011). The Coordination of Agricultural Development with Environment and Resource. The Journal of Quantitative \& Technical Economics, 28, 21-36+49.

Li, N. J., Xiao, X. C., Cao, G. Y., \& He, B. H. (2017). Agricultural Eco-Environment Efficiency and Shadow Price Measurement in Three Gorges Reservoir Area under Non-Point Source Pollution Constraints. Transactions of the Chinese Society of Agricultural Engineering, 33, 203-210.

Liu, S. F., Fang, Z. G., Xie, N. M., Dang, Y. G., Zeng, B., \& Guo, Y. C. (2018). The Theory and Application of Grey System (8th ed.). Science Press.

Liu, X. H., Xu, W. X., Li, Z. J., Chu, Q. Q., Yang, X. L., \& Chen, F. (2013). The Missteps, Improvement and Application of Carbon Footprint Methodology in Farmland Ecosystems with the Case Study of Analyzing the Carbon Efficiency of China's Intensive Farming. Chinese Journal of Agricultural Resources and Regional Planning, 34, 1-11.

Liu, Y. Y., Feng, Z. C., Li, P., \& Ding, Y. M. (2014). Performance and Regional Difference in Chinese Ecological Agriculture. Economic Geography, 34, 24-29.

Liu, Y., \& Song, Y. (2019). Evaluation and Influencing Factor Analysis of Agricultural Water Resource Efficiency in China Based on Super-Efficiency SBM Model. China Rural Water and Hydropower, No. 1, 102-107.

Pan, D., \& Ying, R. Y. (2013). Agricultural Eco-Efficiency Evaluation in China Based on SBM Model. Acta Ecologica Sinica, 33, 3837-3845.

https://doi.org/10.5846/stxb201207080953

State Environmental Protection Administration and General Administration of Quality 
Supervision, Inspection and Quarantine (2002). Environmental Quality Standard for Surface Water GB3838. Standards Press of China.

Tian, W., Yang, L. J., \& Jiang, J. (2014). Measurement and Analysis of the Chinese Agricultural Eco-Efficiency from the Perspective of Low Carbon: Based on SBM Model of the Undesirable Outputs. China Rural Survey, No. 5, 59-71+95.

Tian, X., \& Wang, S. G. (2016). Environmental Efficiency and Its Determinants Regarding China's Grain Production. Resources Science, 38, 2106-2116. https://doi.org/10.18402/resci.2016.11.09

Tian, Y., Zhang, J. B., Wu, X. R., \& Li, G. C. (2015). Growth and Sources of Agricultural Productivity in China under Carbon Emissions Constraint. Journal of Arid Land Resources and Environment, 29, 7-12.

Tone, K. A. (2001). Slacks-Based Measure of Efficiency in Data Envelopment Analysis. European Journal of Operational Research, 130, 498-509. https://doi.org/10.1016/S0377-2217(99)00407-5

Tone, K. A. (2002). A Slacks-Based Measure of Super-Efficiency in Data Envelopment Analysis. European Journal of Operational Research, 143, 32-41.

https://doi.org/10.1016/S0377-2217(01)00324-1

Tong, G. P. (2019). Efficiency Study and Driving Factor Analysis of Agricultural Grey Water Footprint in Huaihe River Basin. MSM Thesis, Nanjing Forestry University.

Wang, B. Y., \& Zhang, W. G. (2016). A Research of Agricultural Eco-Efficiency Measure in China and Space-Time Differences. China Population, Resources and Environment, 26, 11-19.

Wang, B. Y., \& Zhang, W. G. (2018). Cross-Provincial Differences in Determinants of Agricultural Eco-Efficiency in China: An Analysis Based on Panel Data from 31 Provinces in 1996-2015. Chinese Rural Economy, No. 1, 46-62.

Wang, S. Y., \& Lin, Y. J. (2021). Spatial Evolution and Its Drivers of Regional Agro-Ecological Efficiency in China's from the Perspective of Water Footprint and Gray Water Footprint. Scientia Geographica Sinica, 41, 290-301.

Wang, Y. R., Chen, H., \& Han, Z. Y. (2020). Research on Environmental Efficiency of Corn Production in China Based on SBM-Undesirable Model: Taking Heilongjiang Province as an Example. Ecological Economy, 36, 93-98+109.

West, T. O., \& Marland, G. A. (2002). A Synthesis of Carbon Sequestration, Carbone Emissions, and Net Carbon Flux in Agriculture: Comparing Tillage Practices in the United States. Agriculture Ecosystems and Environment, 91, 217-232.

https://doi.org/10.1016/S0167-8809(01)00233-X

Wu, F. L., Li, L., Zhang, H. L., \& Chen, F. (2007). Effects of Conservation Tillage on Net Carbon Flux from Farmland Ecosystems. Chinese Journal of Ecology, 26, 2035-2039.

Zhang, Y. N., Zhang, L. T., \& Han, L. M. (2021). Study on the Evaluation and Promotion Path of Agricultural Ecological Efficiency: An Empirical Analysis of 17 Prefecture Level Cities in Shandong Province. Ecological Economy, 37, 118-124+131.

Zhi, J., \& Gao, J. X. (2009). Analysis of Carbon Emission Caused by Food Consumption in Urban and Rural Inhabitants in China. Progress in Geography, 28, 429-434. https://doi.org/10.1109/ICBBE.2009.5162345

Zhu, N., Cao, B., \& Qin, F. (2018). Research of Wheat Production Efficiency Based on Fertilizer Reduction Potential and Carbon Emission Reduction. China Environmental Science, 38, 784-791. 